deflection at the end of 5 minutes was $460^{\circ}$ on the scale (see accompanying table). This period of time was adopted for this reason, for the duration of each following experiment, though more than needed to produce maximum results. So far the evidence is conclusive that dark heat (i.e. heat capable of melting ice) applied to one side of a piece of ice does not affect the thermopile on the opposite side. So much for the negative results.

It seemed to me at this point worth while to investigate the effects produced by luminous radiant energy of various phases of quality after transmission through ice, which, it would appear, effectually barred the passage of all the obscure rays of the iron ball from even entering it, while the liquefaction of the ice at the surface was beyond all comparison greater than that which goes on at the surface of a glacier even with a full midsummer sun. The sources of luminous energy chosen are given in the first column of the following table. The feeble effect produced by the blue flame of a very large Bunsen lamp (giving no red, orange, or yellow when examined with the spectroscope) as compared with the effects produced by the more highly luminous gas-flames of far inferior thermal intensity (which gave, of course, a complete visible spectrum), is extremely interesting for the light it throws upon the subject in hand. The table of results explains itself at once to any student of physics. The lime-light used, it may be added, was a very powerful one; the sunshine, however, was not very bright or very constant, owing to the drifting of clouds. The latter fact explains the apparent slight anomaly in the results of the solar radiation given in Series II. and III. The observations were made however with the solar radiation (as estimated by a Croo'ses' Radiometer) approximately the same for them all.

Tubie to show the Sifting Power of Ice and Snow upon Radiation of different Phases of Quality

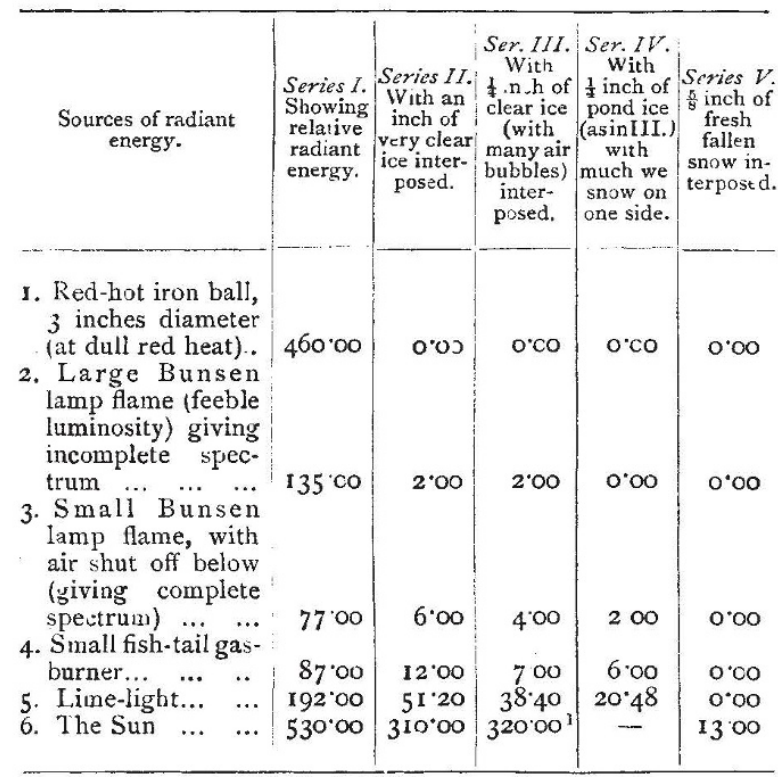

The numbers in each series in the foregoing table do not give very simple relations among themselves, and each number must be regarded as only a near approximation to the exact truth. Still, when all those slight inaccuracies which ari e from "errors of experiment " are allowed for, the general meaning and bearing of the facts remain, namely, that though heat ( $q u \hat{a}$ heat capable as it is of melting ice) cannot enter ice, yet luminous energy, which is readily absorbed and transformed into heat by opaque

${ }^{1}$ In this case a $\frac{1}{4}$-inch plate of clear ice was used. and semi-opaque bodies, can enter and pass through the ice, until it meets with a non-transparent body. Substituting for our thermopile in the experiment, stones, dirt, organic germs, \&c., within the glacier, we at once perceive how the luminous radiant energy of the sun can (by being transformed into dark heat) play its part in producing the movement of glaciers.

Further, this will be found, I believe, the only satisfactory explanation yet given of the remarkable facts ( 1 ) that glaciers move faster (in the Alps about twice as fast) during the summer than during the winter; (2) that the motion during the day is greater than during the night. This fact most people who have written on glaciers have found it difficult to explain, for when the "Regelation Theory" is fully accepted, and all that follows from it is recogmised, and when due allowance is made for internal friction, we still must seek for a cause, independent of both of these, to account for the variations in the movements of glaciers, day and night, summer and winter. This cause has now, I think, no longer to be sought for.

The glacier may be compared to a large greenhouse; as luminous energy enters freely through the glass in the one case, so it enters freely through the transparent ice in the other ; in both cases, heat available for work is produced by its transformation.

In the glacier this work is expended in diminishing the cohesion of the molecules of those parts of the ice which are in contact with the bodies which absorb the luminous energy. The beautiful silvery blue light of an ice-cavern seems to show that a part of a beam of luminous radiation is absorbed by clear ice.

The Series IV. and V. of the table illustrate the effect of $(a)$ the more or less granular condition of the ice in many parts of a glacier, $(b)$ the snow with which the glaciers are covered during the winter. The diffusive action of the latter upon luminous energy is seen by reference to Series V. to be very great; hence the necessity for the use of coloured spectacles on the higher glacier regions.

A. IRVING

\section{DEDUCTIVE BIOLOGY}

$\mathrm{T}$ has probably occurred to a good many readers of NATUke that it would be well if some one were to utter a word of warning as to the mischief which may be done, and especially to students, by the present fashion of explaining all kinds of complicated morphological phenomena in a more or less purely deductive fashion. It is no doubt pleasant, even fascinating, to sit down at one's desk and, having formulated a few fundamental assumptions, to spin out from these explanations of what we see in the world about us. But I think when done it should be understood that the result is merely a literary performance, and though, viewed in that aspect, one may admire the skill and neatness with which it is accomplished, I nevertheless venture to think that the whole proceeding is harmful.

Now, as I shall attempt to illustrate my position by reference to papers which have appeared in NATURE in particular, I may as well say at once that I have no personal or merely controversial object in writing these lines. But though it is now no part of the business of my life to take part in teaching, I have had some experience of it, and a great deal too much of testing its results by the process of examination. I have derived then a tolerably definite idea-as I believe-of the difficulties that beset the imparting of scientific instruction, and a decided conviction as to what sort of discipline is wholesome, and what is mischievous.

Of course I do not deny-far from it-the inspiriting influence which large generalisations impart to teaching. But then I think the intellectual enjoyment of them must be earned. The first thing to do is to put before the student the facts, and then, when these are conscientiously 
mastered, to show what general conclusions may be drawn from them. The student will thus not merely appreciate the mastery which a comprehensive point of view gives of the subordinate facts, but he will get some insight into the value of the evidence upon which the induction rests, and be quite prepared to understand that in the face of a wider survey of observations it may have to be materially modified. This method of procedure seems to me to be not only the scientifically sound one, but to have an educational value of a very high order.

The opposite method is to start with the general principles and derive the explanations from them. This no doubt affords play for ingenuity. But the intellectual discipline is immensely inferior. And when the elaborate structure is built up, it is impossible not to begin insensibly to resent with jealousy any criticism of its foundations, even when it has become difficult to resist the suspicion that they are decrepit. This state of things might be illustrated from the history of the biological sciences again and again. Generalisations which at first were justly hailed with enthusiasm have finally become mischievous obstructions in the way of their adherents arriving at a better knowledge.

I do not mean to say that I prophesy this fate for the evolution theory. But I confess I look with great dislike on the growing tendency, especially in writings intended for popular consumption, to explain everything by it deductively. We may think the probability of organic forms having been evolved is very great. But the how of the process is what in every case we have to prove. In this way the induction on which the theory of evolution rests perpetually widens its base, while at the same time our detailed knowledge of the subordinate laws through which it acts continually accumulates. But if, assuming the truth of the evolution theory, we proceed to spin out of our heads an explanation of how any particular phenomenon came about, I fail to see in what way we are the wiser. The theory of evolution runs a very good chance of being burlesqued; and at the best we find ourselves in possession not of a new knowledge, but merely of an ingenious literary exercise.

In several successive articles, a very able writer, Mr. Grant Allen, has discussed and given a deductive explanation of the shape of leaves. Now this is a matter on which a good many botanists have probably bestowed much thought, and it is well known to be beset with immense difficulties. I believe I am justified in saying that for the last ten years of his life it constantly engaged the attention of Mr. Darwin, and it cannot be doubted that if the problem had at all readily admitted of solution he would have at any rate made some attempt to do for leaves what he did for flowers. In work of this kind Mr. Darwin assumed nothing. His method was purely inductive. He made an immense number of observations drawn from the most widely severed types existing under the most varied conditions, and he gradually felt his way towards some general conclusions. But the fact is that the form of leaves, in common with a great deal of external morphology, is a product of a complex of conditions. Whatever general principles control it, we may be pretty sure that they do not lie on the surface. It is sufficient to mention a few of the obvious factors that must enter into the solution to see that this must be true. In the first place we have the conditions of development; a leaf which, like that of the wild hyacinth, has to be pushed up through compressed soil, must be shaped accordingly, and differently from one, such as that of a horse-chestnut, which languidly expands, like the wings of a butterfly newly escaped from its chrysalis, into the unresisting air. Then we have mechanical conditions; a leaf is a much greater feat of natural engineering than a stem; a fragile expanded structure has to be carried on a single support and supplied with a framework which must bave the necessary rigidity not to collapse, and at the same time be carefully adjusted to withstand wind-strains. Then it must be adapted to meteoric conditions; it must be capable of withstanding solar radiation without being scorched, and its own reduction of temperature at night without being irremediably frozen. With this last circumstance is probably correlated the great variety of nyctitropic movements which leaves execute, and these again react on their form and construction. The enumeration might be very much prolonged; this is only a sample. But it will suggest to most people, as I imagine it did to Mr. Darwin, that, before asserting anything definite about the laws that govern the form of leaves in general, there is an enormous amount to be made out about their relation to particular circumstances of the environment.

But, as far as I can make out, all these considerations count as nothing with Mr. Grant Allen. "Two points," he says, "between them mainly govern the shapes of leaves." One of these is the relation of the leaf to sunlight: and the importance of this no one doubts. The other is the tendency of the plant "to have its whole absorbent surface disposed in the most advantageous position for drinking in such particles of carbonic acid as may pass its way." The importance of this, Mr. Grant Allen adds, "appears hitherto to have been too frequently overlooked."

Now, as I have said, I think the deductive method is a bad way of solving morphological problems. It is still worse when the principle started from is more than doubtful. Mr. Grant Allen speaks of the competition of plants for carbonic acid as of the same kind as that of carnivorous and herbivorous animals for their respective foods. But it is surely nothing of the sort. Carbonic acid is an ingredient of the atmosphere to the extent of $1-2500$ th of its bulk. But only about one-quarter of the earth's surface is occupied by land, and from this a large deduction may be made on account of areas incapable of sustaining vegetation. There is therefore an enormous reserve of atmospheric carbonic acid which, as the atmosphere is rarely at rest, is constantly brought within the range of vegetation. Moreover, the carbon which plays its part in vegetation is continually being released from its organic trammels and the secular accumulation of carbon in the soil, though the work of vegetation is at most extremely slow. On what possible grounds then can Mr. Grant Allen talk of a competition for carbonic acid, which the wind that "bloweth where it listeth" perpetually and $\mathrm{zm}$ partially supplies to the tissues capable of absorbing it? It cannot be doubted that, per unit of absorbent surface, one plant in a locality will get as much carbonic acid as another, no more and no less. And when I say per unit of absorbent surface, I do not mean external surface, which, as well as the shape, I apprehend has nothing to do with the matter. It is of no consequence how the chlorophyll-containing cells which bound the air-passages are massed into a leaf, provided that there is enough of them to do the carbon-fixing work of the plant. When, therefore, Mr. Grant Allen arrives at the conclusion that "the extent to which leaflets are subdivided depends upon the relative paucity of carbon in their environment," I confess that I should much like to see the experimental data, if any, on which this statement rests. As there are plants which at different periods of their lives produce much and little divided leaves, the point would possibly admit of being actually tested.

Now with regard to the submerged foliage of waterplants, I am free to admit that I think Mr. Grant Allen has made a point. These must absorb their carbonic acid superficially, being destitute of stomata and intercellular passages. But I do not see why he should say that the proportion of carbonic acid held in solution by water is very small. It is, I believe, never less than the proportion that occurs in the atmosphere, and may rise to nearly one per cent.

W. T. Thiselton DYER 